\title{
Quality of life related to health in adolescents with type 1 diabetes
}

\author{
Ana Clara Barreto Marini, Camila Rodrigues da Cunha Santos, Jéssika Martins Siqueira, \\ Rosana de Morais Borges Marques* \\ From 20th Brazilian Diabetes Society Congress \\ Porto Alegre, Brazil. 11-18 November 2015
}

\section{Background}

The knowledge of the influence of type 1 diabetes on quality of life (QL) of adolescents is important due to the intensive care imposed by the treatment that requires changes in their routine. Therefore, identify the QL contributes to comprehension of the health state and the difficulties of adolescents that are essential for planning measures to improve adherence to treatment. Objective: To evaluate the quality of life related to health of adolescents with type 1 diabetes (T1D).

\section{Materials and methods}

A cross-sectional study was conducted in June 2015 (CEP 078/2011) with adolescents aged 10 to 18, diagnosed with T1D for over a year. We collected socioeconomic, demographic, health status, insulin therapy and metabolic control data. The instrument used to measure quality of life was IQVJD (NOVATO, 2008). The data were analyzed by SPSS version 18.0.

\section{Results}

The study included 53 adolescents (52.8\% female; $37.8 \%$ aged 16-18 yrs.), most was attending the middle school (52.8\%). About sanitation and income conditions, 15.1\% and $54.7 \%$ didn't have treated water supply and sewerage, respectively, and $36.0 \%$ had monthly per capita income less than two minimum wages. $62.7 \%$ of the adolescents were diagnosed with T1D before complete 10 yrs. of age. Almost all reported making home glucose monitoring (96.2\%), $41.5 \%$ for at least three times per day. Complications of diabetes were found in $11.3 \%$ of participants, and the median of HbA1c was 9.7\% (6-20) and average of $251.50 \mathrm{mg} / \mathrm{dL}$ for fasting glucose. The predominant insulin regimen was the intensive with multiple doses, and only $53.9 \%$ did rotation of application sites. Regarding nutritional status, $21.2 \%$ and $23.5 \%$ were overweight and in cardiovascular risk, respectively. The analysis of IQVJD demonstrated that $77.4 \%$ were classified as improved QL. As for the domain satisfaction, only $67.9 \%$ had better QL, and in the areas impact and concern, $73.6 \%$ and $62.3 \%$ showed better QL, respectively. We observed that only $47.2 \%$ reported good health compared with other teens at the same age.

\section{Conclusions}

The high prevalence of adolescents with poorer QL in the areas satisfaction and concern, as well as in the selfperception of their health, may indicate that the presence of disease and health care that is required, influence negatively in adolescent life, which could affect their adherence to treatment and increase the risk of developing chronic complications.

Published: 11 November 2015

doi:10.1186/1758-5996-7-S1-A180

Cite this article as: Marini et al:: Quality of life related to health in adolescents with type 1 diabetes. Diabetology \& Metabolic Syndrome 2015 7(Suppl 1):A180.

* Correspondence: rosanambm@gmail.com

Universidade Federal de Goiás, Goiânia, Brazil

(C) 2015 Marini et al. This is an Open Access article distributed under the terms of the Creative Commons Attribution License (http:// creativecommons.org/licenses/by/4.0), which permits unrestricted use, distribution, and reproduction in any medium, provided the original work is properly cited. The Creative Commons Public Domain Dedication waiver (http://creativecommons.org/publicdomain/ zero/1.0/) applies to the data made available in this article, unless otherwise stated. 